\title{
Exposure to bisphosphonates and risk of gastrointestinal cancers: series of nested case-control studies with QResearch and CPRD data
}

\author{
(c) (1) (8) OPEN ACCESS
}

\section{Yana Vinogradova research fellow in medical statistics, Carol Coupland associate professor and reader in medical statistics, Julia Hippisley-Cox professor of clinical epidemiology and general practice}

Division of Primary Care, University Park, Nottingham NG2 7RD, UK

\begin{abstract}
Objective To investigate the association between use of bisphosphonates estimated from prescription information and risk of gastrointestinal cancers.

Design Series of nested case-control studies.

Setting General practices in the United Kingdom contributing to the QResearch primary care database (660) and the Clinical Practice Research Datalink (CPRD) (643).

Participants Patients aged $\geq 50$ with a diagnosis of a primary gastrointestinal cancer in 1997-2011, each matched with up to five controls by age, sex, practice, and calendar year.
\end{abstract}

Main outcome measures Odds ratios for incident gastrointestinal cancers (colorectal, oesophageal, gastric) and use of bisphosphonates, adjusted for smoking status, ethnicity, comorbidities, and use of other drugs.

Results 20106 and 19035 cases of colorectal cancer cases, 5364 and 5135 cases of oesophageal cancer cases, and 3155 and 3157 cases of gastric cancer were identified from QResearch and CPRD, respectively. Overall bisphosphonate use (at least one prescription) was not associated with risk of colorectal, oesophageal, or gastric cancers in either database. Adjusted odds ratios (95\% confidence interval) for QResearch and CPRD were 0.97 (0.79 to 1.18) and 1.18 (0.97 to 1.43) for oesophageal cancer; $1.12(0.87$ to 1.44$)$ and $0.79(0.62$ to 1.01$)$ for gastric cancer; and 1.03 (0.94 to 1.14) and 1.10 (1.00 to 1.22) for colorectal cancer. Additional analyses showed no difference between types of bisphosphonate for risk of oesophageal and colorectal cancers. For gastric cancer, alendronate use was associated with an increased risk $(1.47,1.11$ to $1.95 ; P=0.008)$, but only in data from the QResearch database and without any association with duration and with no definitive confirmation from sensitivity analysis.

Conclusions In this series of population based case-control studies in two large primary care databases, exposure to bisphosphonates was not associated with an increased risk of common gastrointestinal cancers.

\section{Introduction}

As an established drug for the treatment and prevention of osteoporosis,,${ }^{12}$ bisphosphonates have been widely prescribed ${ }^{3}$ and have a long term effect. ${ }^{4}$ Although preclinical studies have shown that bisphosphonates have anti-tumour properties, ${ }^{56}$ there is still a possibility that their adverse effects on the gastrointestinal tract, such as mucosal irritation, might cause ulceration ${ }^{7}$ and could be linked to an increased risk of cancer.

The first publication on the possible association was from the US Food and Drug Administration (FDA) Adverse Event Reporting System, which listed 23 cases of oesophageal cancer in users of oral alendronate between 1995 and $2008 .^{8} \mathrm{An}$ observational study, however, showed a reduced risk for oesophageal cancer but not gastric cancer. ${ }^{9}$ A nested case-control study, based on the General Practice Research Database (GPRD), showed a 30\% increased risk of oesophageal cancer in bisphosphonate users ${ }^{10}$ rising to more than a twofold increase in risk for more than three years' use, but it did not find a significant association with risk of gastric or colorectal cancers. A cohort study based on the GPRD, however, did not find any significant association between bisphosphonate use and risk of gastric or oesophageal cancers. ${ }^{11}{ }^{12}$ One Danish cohort study looked at gastrointestinal cancers and reported an increased risk of oesophageal cancer associated with use of alendronate and a possible protective effect of higher doses for colorectal cancer. ${ }^{13}$ Finally, another Danish cohort study showed a reduced risk of gastric cancer and no excess risk in oesophageal cancer ${ }^{14}$ in alendronate users. As for colorectal cancer, another cohort analysis that used the GPRD found a reduced risk associated with bisphosphonate use, ${ }^{11}$ and an Israeli study also showed a significantly decreased risk in patients taking bisphosphonates for more an year. ${ }^{15}$ Although a Danish study on postmenopausal women showed a reduced risk of colorectal cancer with oral bisphosphonates, the association was not time or dose dependent. $^{16}$ 
In summary, studies to date have reported conflicting findings, were based on data collected only up to 2008 , and were limited by statistical power. We therefore investigated the association between bisphosphonates used for the prevention or treatment of osteoporosis and the risk of gastrointestinal cancers in the general population with a nested case-control design and including the most recent data from the QResearch database in the United Kingdom. We also replicated the analyses using the Clinical Practice Research Datalink (CPRD, previously known as General Practice Research Database (GPRD)).

\section{Methods}

\section{Study design}

The protocol for this study was published in $2012^{17}$ and identified the QResearch UK primary care database as a source of data. Simultaneously, with the same protocol, a replicate study was conducted with CPRD. These databases are the largest primary care datasets in the UK and contain electronic records from 660 (QResearch) and 643 (CPRD) general practices, which include patients' demographics, referrals, tests, and prescriptions. Both have been successfully validated with other sources of information ${ }^{18}{ }^{19}$ and have been used for a range of safety studies involving commonly prescribed drugs. ${ }^{10} 202122$

We identified open cohorts of patients aged $\geq 50$ and registered with the practice at some time during the study period (January 1997 to July 2011). For this paper we selected gastrointestinal cancers (oesophageal, gastric, and colorectal) as the outcome and identified incident cases from the cohorts. The design of the study was a nested case-control study. We excluded patients aged $<50$ because the risk of the cancers of interest is low in this group and because bisphosphonates are rarely prescribed in younger people. We matched each case with up to five controls by age, sex, practice, and calendar year. All controls were alive and registered with the practice at the date of the first recorded diagnosis of cancer in their matched case, which we defined as the index date for each case and their matched controls. We excluded cases and controls with prescriptions for bisphosphonates licensed for any malignancies before the index date. Patients with Paget's disease were also excluded as their treatment requires higher doses of bisphosphonates and for much longer periods. Patients were included only if they had at least two years of data before their index date to ensure the completeness of records.

\section{Exposure to bisphosphonates}

The primary measure of exposure to bisphosphonates was assessed from prescription information within the observation period from the date of patient's registration with the practice to six months before the index date. Prescriptions in the last six months were ignored to reduce protopathic bias - early symptoms of cancer might include weight loss and low bone mineral density and be mistaken for symptoms of osteoporosis. A patient was considered to be a bisphosphonate user if they had at least one prescription in the observation period. The bisphosphonates to be included were identified in the British National Formulary section 6.6.2 as treatment for osteoporosis: alendronate, etidronate, ibandronate, and risedronate. We considered type of regimen for bisphosphonate use-daily or weekly/monthly_-because daily use has been shown to have lower adherence than weekly use, with one of the possible reasons being inconvenience, ${ }^{23}$ and we investigated possible differences between the effects of daily and other exposures to bisphosphonates on risk of gastrointestinal cancers. Cumulative exposure was estimated by summing the prescribed durations of prescription for each patient, considering gaps of fewer than 60 days between proximate prescriptions as continuous treatment. For drugs prescribed in cycles, the cycle length was taken to be the duration of prescription. Duration of use of bisphosphonates in the observation period (excluding the six months before the index date) was analysed with the following categorisations: no use; $<6$ months; 7-36 months; $37-72$ months; $\geq 73$ months. A test for trend was performed with the actual number of months.

\section{Confounding variables}

All the analyses included potential confounders established as risk factors for cancer. Body mass index (BMI $)^{24}$ as a continuous variable was measured at the date closest to one year before the index date. Smoking status ${ }^{25}$ (current smoker: light (1-9 cigarettes/day), medium (10-19), heavy ( $\geq 20$ ), ex-smoker, non-smoker); alcohol consumption ${ }^{26}$ using Read codes for alcohol status; and ethnicity ${ }^{27}$ (white or not recorded, black, Asian, other) were based on the latest values recorded before the index date. The analysis also adjusted for history of osteoporosis ${ }^{28}$ including a diagnosis of osteoporosis or osteopenia or previous fractures recorded before the index date; use of drugs that impair calcium absorption and reduce bone density or that affect risks of cancer such as systemic corticosteroids and acid suppressive drugs (including $\mathrm{H}_{2}$ antagonists (BNF 1.3.1), proton pump inhibitors (BNF 1.3.5), and antacids $(B N F \text { 1.1.1) })^{29} 30$; use of anti-inflammatory drugs ${ }^{31}$ (traditional non-steroidal (NSAIDs), cyclo-oxygenase-2 inhibitors and aspirin) ${ }^{32}$; and use of vitamin $\mathrm{D}^{33}$ if they were prescribed at least one year before the index date. Use of acid suppression drugs was categorised by the number of prescriptions within the observation period: none; $<12$ prescriptions; $12-24$ prescriptions; $25-48$ prescriptions; and $\geq 49$ prescriptions to distinguish between occasional and more regular use.

We also included comorbidities that affect the risks of cancer (such as rheumatoid arthritis ${ }^{34}$ for any cancer and diabetes for colorectal cancer $^{35}$ ) if they were diagnosed at least a year before the index date. Analyses were adjusted for gastrointestinal disorders ${ }^{36}$ if they were diagnosed before the first use of bisphosphonates or 12 months before the index date, whichever was earlier; diseases included upper gastrointestinal disease (dysphagia, oesophagitis, gastro-oesophageal reflux disease, hiatus hernia, oesophageal ulcers, Barrett's oesophagus, gastritis, duodenitis, peptic ulcers, dyspepsia), Crohn's disease, and ulcerative colitis. The results were also adjusted for family history of cancer $^{37}$ (this varied according to the cancer under consideration) if it was recorded at least six months before the index date. This is to reduce recall bias as patients are more likely to report a family history of cancer around the time of diagnosis. ${ }^{38}$

\section{Statistical analysis}

Analyses for these two studies were carried out separately in the two databases. We used conditional logistic regression to estimate odds ratios with $95 \%$ confidence intervals for cancer for each selected site and Wald test to examine the effects of duration and the differences in these between types of bisphosphonates. Missing values for the confounding factors (BMI, smoking status, and alcohol intake) were imputed with multiple imputation with the ICE programs in Stata. ${ }^{39}{ }^{40} \mathrm{We}$ created 10 imputed datasets including all potential confounders and bisphosphonate exposure in the models and combined the results using Rubin's rules. ${ }^{39}$ Results from both analyses were 
pooled with the Mantel-Haenszel method for fixed effect models.

The primary analyses were based on exposure to bisphosphonates excluding prescriptions in the six months before the index date. We were carried out five sensitivity analyses. Firstly, having only one prescription in their records might mean that a patient never started bisphosphonate treatment or stopped it early because of adverse side effects, so we ran an analysis defining use of bisphosphonates as at least two prescriptions, but still excluding any in the last six months before the index date. In the second sensitivity analysis we included prescriptions in the last six months and considered a patient to be a user if they had at least one prescription in their records at any time before the index date.

Another possible bias in the main analysis might arise from the different observation times for patients so we undertook a third sensitivity analysis selecting patients only if they had at least six years of records and including prescriptions only between 6 and 72 months before the index date. Because Townsend score as a measure of deprivation was available for only $49 \%$ of CPRD practices we did not include it as a confounding variable in the main analyses in either database, so a fourth sensitivity analysis, restricted to patients with a valid Townsend score and adjusting for this, was run in both databases. A fifth sensitivity analysis was run with data only for patients with complete records for BMI, smoking, and alcohol intake. For the fourth and fifth sensitivity analyses, the definitions for use of bisphosphonates and years of medical records were identical to those in the main analysis.

All available data were used in the analyses and to allow for multiple comparisons we considered $\mathrm{P}<0.01$ as significant, but to create a parity of presentation with other studies we have quoted a $95 \%$ confidence interval in our results. Sample size calculations are presented in the protocol. ${ }^{17}$ Stata version 12 was used for the analyses.

\section{Results}

\section{Study population}

Within the study period, in QResearch we identified 20106 cases of colorectal cancer, 5364 cases of oesophageal cancer, and 3155 cases of gastric cancer matched to 93954,25101 , and 14715 controls, respectively. From CPRD, there were 19 035 cases of colorectal cancer, 5132 cases of oesophageal cancer, and 3157 cases of gastric cancer matched to 89111,24 053, and 14686 controls, respectively.

Tables 1, 2 and $3 \Downarrow \Downarrow \Downarrow$ show the characteristics for all cases and controls for both databases. Most of the descriptive statistics were similar in QResearch and CPRD. Cases and controls from QResearch were slightly younger than CPRD cases and controls, and Townsend score as a measure of deprivation was available only for a third of cases and controls in CPRD (table $1 \Downarrow$ ). BMI, smoking status, and alcohol consumption had slightly fewer missing values in CPRD with higher proportions of non-smokers and moderate and high alcohol consumption than in QResearch (table $2 \Downarrow$ ).

Most of the comorbidities had similar proportions in cases selected from both databases and their controls (table $3 \Downarrow$ ). Upper gastrointestinal morbidities were recorded slightly more often in CPRD (29\% in cases and $27 \%$ in controls $v 22 \%$ and $20 \%$ in QResearch) with higher proportions for gastro-oesophageal reflux (9\% and $8 \% v 6 \%$ and $5 \%$, respectively) and dyspepsia (13\% and $12 \% \vee 7 \%$ and $7 \%$, respectively). Use of common drug treatments was similar in the databases with slightly more frequent prescribing of NSAIDs and less frequent prescribing of corticosteroids in CPRD compared with QResearch.

Prescribing of calcium supplements also had different patterns with more patients prescribed calcium in CPRD.

\section{Patterns of bisphosphonate use}

In QResearch $4.6 \%$ of cases and $4.5 \%$ of controls had one or more prescriptions for bisphosphonates, as did $4.8 \%$ and $4.6 \%$, respectively, in CPRD. About two thirds of patients with a diagnosis of osteoporosis had been prescribed bisphosphonates (64\% of cases and 65\% of controls in QResearch and $61 \%$ and $60 \%$, respectively, in CPRD) and $2 \%$ of cases and controls in both databases had prescriptions for bisphosphonates without records of osteoporosis. Bisphosphonate users were more likely to be women and to have a lower BMI. Upper gastrointestinal problems were slightly more common (QResearch: cases $25 \%$ in users $v 22 \%$ in non-users, controls $25 \% v 20 \%$; CPRD: cases $35 \%$ v $29 \%$, controls $33 \% \vee 27 \%$ ) and use of acid lowering drugs was much more common in bisphosphonate users (QResearch: cases 62\% in users $v 37 \%$ in non-users, controls $61 \%$ v 32; CPRD: cases $65 \%$ v 39\%, controls $63 \%$ v35\%). Among bisphosphonate users, the proportion of patients with rheumatoid arthritis was more than five times higher than in non-users, and there were similar patterns for use of anti-inflammatory drugs, non-steroidal drugs, and corticosteroids.

More than three quarters of the bisphosphonate users were prescribed only one type of drug $(77 \%$ in cases and $77 \%$ in controls in QResearch and 80\% and 79\% in CPRD), one fifth had prescriptions for two different types (20\% in cases and $20 \%$ in controls in QResearch and $17 \%$ and $19 \%$ in CPRD), and less than 3\% (2\% in cases and 3\% controls in QResearch and 3\% and $2 \%$ in CPRD) had prescriptions for three different types during the observation period. Alendronate was the most commonly prescribed type (69\% in cases and 66\% in control users in QResearch and 69\% and 69\% in CPRD) and mostly prescribed for weekly use ( $87 \%$ in cases, $88 \%$ in controls in QResearch and $89 \%$ and $88 \%$ in CPRD). The second most common type was etidronate (34\% in cases and $36 \%$ in controls users in QResearch and 30\% and 32\% in CPRD) with daily use for 14 days in 90 day cycles. The third most common was risedronate $(21 \%$ in cases and $22 \%$ controls users in QResearch and $22 \%$ and $21 \%$ in CPRD), prescribed mostly for weekly use (76\% in cases and $80 \%$ in controls users in QResearch and $82 \%$ and $81 \%$ in CPRD). Ibandronate (2\% in cases and in controls users in QResearch and CPRD) was prescribed for monthly use only and no one received it as injections. In only one case (in QResearch) was a patient prescribed zoledronic acid.

In both databases, the minimum duration of bisphosphonate prescription was one week, and over half of bisphosphonate users had prescriptions for at least 20 months (median 20 (interquartile range 7-43) and 21 (8-44) for cases and controls, respectively, for QResearch; 19 (6-4) and 20 (7-41) for CPRD). Two thirds of bisphosphonate users (64\% cases and $65 \%$ controls in QResearch, and 63\% cases and controls in CPRD) had no gap of longer than 60 days between the first and last prescriptions, with $17 \%$ of cases and $18 \%$ of controls in QResearch and 19\% of cases and 20\% of controls in CPRD having only one gap longer than 60 days.

\section{Associations with cancer}

Tables $4 \Downarrow, 5 \Downarrow$, and $6 \Downarrow$ show the associations between regimen and duration of bisphosphonate prescriptions and different types of the drug and risk for oesophageal, gastric, and colorectal 
cancer. Table $7 \Downarrow$ contains the results from the first three sensitivity analyses for short and long term use for the three cancers.

\section{Oesophageal cancer}

After adjustment for confounders, both studies showed no significant association between overall bisphosphonate use and risk of oesophageal cancer (adjusted odds ratio $0.97,95 \%$ confidence interval 0.79 to 1.18 , for QResearch; and 1.18, 0.97 to 1.43 , for CPRD). Similarly, there were no differences for frequency of use or duration ( $\mathrm{P}=1.0$ for trend) in QResearch. In $\mathrm{CPRD}$, although odds ratios were progressively higher for longer use of bisphosphonates, none of them nor the trend test reached significance ( $\mathrm{P}=0.07$ for trend). There were no significant associations for individual types of bisphosphonate. None of the sensitivity analyses showed any significant associations.

\section{Gastric cancer}

After adjustment for confounders, both studies showed no significant association between overall bisphosphonate use and risk of gastric cancer (adjusted odds ratio 1.12, 95\% confidence interval 0.87 to 1.44 , for QResearch, and $0.79,0.62$ to 1.01 , for CPRD). Daily use of bisphosphonates was associated with a decreased risk $(0.60,0.41$ to $0.87 ; \mathrm{P}=0.008)$ in $\mathrm{CPRD}$, but this was not confirmed by any of the sensitivity analyses. Of the different bisphosphonates, alendronate use was significantly associated with cancer risk only in QResearch $(1.47,1.11$ to 1.95; $\mathrm{P}=0.008)$, but a direct test between the different types of bisphosphonates was not significant $(\mathrm{P}=0.053)$. Short term use $(<1$ year) of alendronate was associated with a significantly higher risk of cancer in QResearch $(1.91,1.34$ to $2.72 ; \mathrm{P}<0.001)$, but there was no significant increase for longer term use (1.08, 0.74 to $1.59 ; \mathrm{P}=0.7)$. These findings were also significant in the first sensitivity analysis, which classified use as two or more prescriptions ( $2.23,1.54$ to $3.22 ; \mathrm{P}<0.001$ for shorter term), but results of the second sensitivity analysis, which classified use as all prescriptions including the last six months, failed to reach significance $(1.49,1.06$ to $2.08 ; \mathrm{P}=0.02$ for shorter term). In CPRD, the odds ratio for alendronate use $(0.93,0.71$ to 1.22$)$ was also higher than for other bisphosphonates, but the difference between drugs was not significant $(\mathrm{P}=0.2)$. There were no significant relations with duration for any of the drugs. No other significant associations were observed in the sensitivity analyses.

\section{Colorectal cancer}

Use of bisphosphonates was similar in cases of colorectal cancer and their matched controls ( $4.6 \%$ in both), and adjustment for the confounders did not show any association between bisphosphonate use and risk of cancer (adjusted odds ratio 1.03, $95 \%$ confidence interval 0.94 to 1.14 , for QResearch; and 1.10, 1.00 to 1.22 , for CPRD). Daily use had similar effects as weekly or monthly use. In CPRD data, short term use was associated with an increased risk, although this reached significance only for one to six months' use $(1.27,1.09$ to $1.48 ; \mathrm{P}=0.002)$, but this finding was not confirmed by any of the sensitivity analyses. The relation between duration of bisphosphonate use and risk of colorectal cancer was not significant in either database $(\mathrm{P}=0.3$ for trend for QResearch and P=0.5 for CPRD). For QResearch, the adjusted odds ratio for any use of alendronate was higher than for etidronate or risedronate, but it was not significantly increased and the difference between the drugs was not significant $(\mathrm{P}=0.09)$. For $\mathrm{CPRD}$, the effect of drugs seemed to be similar $(\mathrm{P}=0.5)$. The results from the sensitivity analyses were in line with these.

Results obtained from pooling the results from both databases presented in tables 4,5 , and 6 did not show any significant findings.

\section{Discussion}

\section{Summary}

This series of case-control studies on two large population databases found no overall association between use of bisphosphonates and risk of oesophageal, gastric, or colorectal cancer. There was a small significantly increased risk of gastric cancer associated with use of alendronate in one database, which was restricted to short term alendronate users; the risk was nearly twofold for patients who used alendronate for less than a year. This is unlikely to be a causal relation as there was no association with longer term use. For colorectal and oesophageal cancers, there were no associations that suggested an increased risk of these cancers in people using bisphosphonates.

\section{Strengths and limitations}

This was the first drug safety study to be undertaken with both CPRD and QResearch databases with identical definitions for confounders, exposures, and sampling to help ensure comparability. As an observational study based on routinely collected data from two large primary care research databases, it has the strengths and limitations common to such studies. Our study was substantially larger and had much greater statistical power than any previous study. This allowed analyses to be carried out to investigate the effects of duration of treatment on risk of cancer. As the data on prescriptions and potential confounding variables were routinely and prospectively collected and recorded before the index date, the study was free from recall bias. Because all eligible cases and randomly selected controls were included, there was also no selection bias.

The limitations of the study include possible uncertainty in records of diagnosis of cancer. A systematic review based on GPRD validation studies reported that, on average, $95 \%$ of diagnoses of cancer recorded on the general practice electronic record were confirmed from other data sources. ${ }^{41}$ It has been found, however, that one in five of all primary care patients with cancer were not identified through electronic searches for malignancies in general practice electronic records, although this was based on data from 1990-99..$^{42}$ Any such misclassification might result in underestimation of associations with bisphosphonates, shifting odds ratios toward unity. Also, the selection of cases was based on the first record of a cancer while the exact origin site might have been determined only later, and this level of detail was not available across all records. Information about cancer stage or results of histological investigations was also not consistently recorded in general practice, so was not used. Within each site of origin, this creates an inability to distinguish between specific cancers that might have different risk factors.

Another limitation is that there might have been an overestimation of bisphosphonate use. The analyses were based on prescriptions rather than actual use, and no data were available on adherence to treatment. There is, however, no reason for non-adherence to systematically differ between cases and controls.

There could have been some residual confounding as information on some risk factors such as bone mineral density, physical activity, diet, and cancer screening tests (endoscopy 
or colonoscopy) is not generally recorded so these factors were not included in the analyses.

\section{Bisphosphonate users}

Comparisons between bisphosphonate users and non-users reflected the recommendations for targeting groups with osteoporosis, as some characteristics and comorbidities, such as low BMI and rheumatoid arthritis in users, are associated with diagnosis of primary osteoporosis. A heightened rate of upper gastrointestinal disorders before onset of treatment for osteoporosis has also been reported elsewhere..$^{43}$ As secondary osteoporosis is more likely to develop in patients taking acid lowering drugs ${ }^{29}$ and corticosteroids,${ }^{44} 4$ the proportion of such patients was noticeably higher in bisphosphonate users. Although upper gastrointestinal disorders and use of acid lowering drugs could be important confounders, they might also lie on the causal pathway. Removal of them from the adjusted analyses, however, did not noticeably change the results.

\section{Oesophageal cancer}

Oesophageal cancer associated with bisphosphonate use has been of most concern to epidemiologists. So far, however, the studies of this association have all been much smaller than our study, which was based on 252 bisphosphonate users with oesophageal cancer in QResearch and 262 in CPRD, and have yielded inconsistent results.

The study by Green and colleagues, which was based on an earlier version of CPRD with larger proportions of missing values and more exposure to etidronate than alendronate $(57 v$ 37 exposed cases), reported an association with duration of treatment, with an over twofold increase in people who had been taking these drugs for more than three years (33 such cases).$^{10}$ These results were, however, adjusted only for smoking status, alcohol intake, and BMI, without adjustment for the important confounders of osteoporosis and use of any drugs other than bisphosphonates associated with its treatment, so possibly overestimating cancer risk. Similarly, another recent study on GPRD data from 1995 to 2007 showed an increased risk of oesophageal cancer associated with bisphosphonate use, but only in women (adjusted odds ratio 1.43, 95\% confidence interval 1.16 to 1.75 ), and again the results were not adjusted for osteoporosis or drugs associated with it. ${ }^{46}$ There seemed to be an opposite association for men (adjusted odds ratio 0.73, 0.53 to 1.03 ), although it was not significant. A Taiwanese case-control study analysed prescription information from 16 204 cases and 64816 controls and reported no association for overall exposure and increased risk only in rare users, but this study did not adjust for any confounding factors. ${ }^{47}$

The cohort study by Cardwell and colleagues, ${ }^{11}$ which also used the CPRD database, identified 79 cases of oesophageal cancer in bisphosphonate users and did not report a significantly increased risk of cancer even for cumulative exposure of more than three years (hazard ratio $0.90,0.44$ to 1.81 ). In our CPRD analyses, use for more than three years was associated with an increased risk ( 92 such cases, odds ratio $1.38,95 \%$ confidence interval 1.04 to $1.84 ; \mathrm{P}=0.03$ ), but this was not significant at the $1 \%$ level. In our QResearch analyses, we did not observe an increased risk of oesophageal cancer in bisphosphonate users but rather showed a reduced, but again not significant, risk for people who had been taking these drugs for more than three years (75 such cases, odds ratio $0.92,0.68$ to 1.25 ).

Although Vestergaard's study showed significantly increased risks of oesophageal cancer in etidronate and alendronate users (32 and 14 cases, respectively), ${ }^{13}$ these associations were not time dependent and therefore might not be causal. Another cohort study looking at alendronate and etidronate use reported a decreased risk of oesophageal cancer for both, ${ }^{14}$ although not significant, and showed even greater reduction in patients with 10 prescriptions or more, but this was still not significant.

\section{Gastric cancer}

In line with our findings, no association between use of any bisphosphonates and gastric cancer has been reported in previous CPRD publications. ${ }^{10}{ }^{12}$ Our CPRD analyses had similar findings to those of Green and colleagues ${ }^{10}$ for gastric cancer on the same database and, despite a bigger sample, did not reach a significant level for the association of a decreased risk with bisphosphonate use. Our QResearch analyses showed an opposite association for gastric cancer and use of alendronate to the one found in the study by Abrahamsen and colleagues (39\% reduced risk based on 22 exposed cases $)^{14}$ but our association, an almost twofold increased risk, was seen only in short term users, with no association for long term use. In our CPRD analyses, however, we found no association with alendronate use. It is possible that this short term association resulted from users stopping bisphosphonate treatment because the drugs caused side effects similar to symptoms of gastric cancer or aggravated early symptoms of gastric cancer, leading to earlier detection of existing cancer. It has been shown that alendronate in particular might be associated with gastrointestinal mucosal injury, ${ }^{48}$ which would require additional tests. Given the lack of consistency between the CPRD and QResearch results, however, this might simply be a spurious chance finding, and it is unlikely to reflect a causal association.

The paper by Cardwell and colleagues noted that there are possible misclassifications of gastric and oesophageal cancers, and that study showed no association between bisphosphonate use and risk of those cancers when combined. ${ }^{11}$ To check this, we ran a combined analysis to compare our findings and also did not observe any significant association in either database (overall use for QResearch odds ratio 1.02, 95\% confidence interval 0.88 to 1.20 ; and $1.02,0.87$ to 1.18 , for CPRD), all P values being greater than 0.1 except for short term alendronate use in QResearch (odds ratio 1.29, 1.03 to 1.60; $\mathrm{P}=0.02$ ).

\section{Colorectal cancer}

Based on 20106 cases of colorectal cancer in QResearch and 19035 in CPRD with, respectively, 929 and 902 cases exposed to bisphosphonates, our study found no association between bisphosphonate use and risk of colorectal cancer. The increased risk found in the CPRD analysis and associated only with short term use (up to six months) was inconsistent with the QResearch findings and not confirmed in sensitivity analyses. Similarly inconsistent results have been found in other smaller epidemiological studies. ${ }^{10}{ }^{12}{ }^{13}$ Two studies-Cardwell et al ${ }^{12}$ and Green et $\mathrm{al}^{10}$ - that used CPRD and based, respectively, on 264 and 276 bisphosphonate users, found similar associations for risk of colorectal cancer, but reached significant levels only in one ${ }^{12}$ (hazard ratio for any use $0.74,95 \%$ confidence interval 0.60 to 0.91 ). Cardwell and colleague's study, ${ }^{12}$ however, used an earlier version of the same data source and had much higher proportions of missing data for BMI, smoking, and alcohol consumption, all factors associated with both bisphosphonate prescribing and risk of cancer. Another study, which used an Israeli health services database, also reported a decreased risk of colorectal cancer in bisphosphonate users (odds ratio for any use $0.67,95 \%$ confidence interval 0.51 to 0.88$).{ }^{15}$ This was based on only 97 cases in users and was subject to recall and selection biases, with different response rates for cases and 
controls (83\% and 58\%, respectively). An American study on menopausal women enrolled in the Nurses Health Study reported no association either for overall use of bisphosphonates or for different terms of use. ${ }^{49}$ Although a recent Danish study showed an association between overall use of bisphosphonate and reduced risk of colorectal cancer (hazard ratio $0.69,95 \%$ confidence interval 0.60 to 0.79 ) and even described a possible mechanism based on anti-tumour properties of the drug, the study did not show any dose or time dependent associations, and the risk of cancer was not significantly reduced in long term (more than six months) users (hazard ratio $0.78,0.55$ to 1.11 ). ${ }^{16}$

\section{Conclusion}

We have conducted a series of large population based case-control studies using the two largest primary care databases in the UK to examine the association of bisphosphonates with risks of common gastrointestinal cancers in the general population. The databases provided almost the same numbers of cases and controls and the recorded data were similar in demographics, lifestyle related factors, comorbidities, and use of drugs. Although several findings were consistent between the databases, we found no increased risk in general for any of the cancers except for an increased risk of gastric cancer in alendronate users in one of the databases, but without time associations.

We acknowledge the contribution of EMIS and the University of Nottingham for expertise in creating and maintaining QResearch, and to the EMIS practices that contribute data, without whom this research would not be possible.

Contributors: $\mathrm{JH}-\mathrm{C}$ had the original idea for this study. CC contributed to the development of the idea and the study design. $\mathrm{YV}$ reviewed the literature, contributed to the study design, undertook the primary analysis and the first interpretation, and wrote the first draft of the paper. $\mathrm{JH}-\mathrm{C}$ and $\mathrm{CC}$ critically reviewed the paper. All authors approved the submitted version. $\mathrm{YV}$ is guarantor.

Funding: This work was funded by the division of primary care of University of Nottingham.

Competing interests: All authors have completed the Unified Competing Interest form at www.icmje.org/coi_disclosure.pdf (available on request from the corresponding author) and declare no support from any additional organisation for the submitted work. $\mathrm{JH}-\mathrm{C}$ is an unpaid director of QResearch, a not-for-profit organisation that is a joint partnership between the University of Nottingham and EMIS (commercial IT supplier for $60 \%$ of general practices in the UK). JH-C is also a paid director of ClinRisk, which produces open and closed source software to ensure the reliable and updatable implementation of clinical risk algorithms within clinical computer systems to help improve patient care.

Ethical approval: This protocol has been published in BMJ Open. It has also independently peer reviewed by the QResearch Scientific Board and has been reported to Trent research ethics committee in accordance with the agreed procedure (reference No MREC/03/4/021). For CPRD data analysis, the protocol was approved by independent scientific advisory committee (reference No ISAC 11_149).

Data sharing: Descriptive statistics for users and non-users of bisphosphonates and results of unadjusted and sensitivity analyses are available from the corresponding author.

1 National Institute for Health and Clinical Excellence. Alendronate, etidronate, risedronate, strontium ranelate and raloxifen for preventing bone fractures in postmenopausal women with osteoporosis who have not had a fracture. Information about NICE technology appraisal guidance No 160. NICE, 2008.

2 National Institute for Health and Clinical Excellence. Alendronate, etidronate, risedronate, strontium ranelate and teriparatide for preventing bone fractures in postmenopausal women with osteoporosis who have already had a fracture. Information about NICE technology appraisal guidance No 161. NICE, 2008.
3 Kanis J, McCloskey E, Johansson H, Strom O, Borgstrom F, Oden A. Case finding for the management of osteoporosis with FRAX®_-assessment and intervention thresholds for the UK. Osteoporos Int 2008;19:1395-408.

4 Watts NB, Diab DL. Long-term use of bisphosphonates in osteoporosis. J Clin Endocrinol Metab 2010;95:1555-65.

5 Guise TA. Antitumor effects of bisphosphonates: promising preclinical evidence. Cancer Treat Rev 2008;34(suppl 1):S19-24.

6 Croucher P, Jagdev S, Coleman R. The anti-tumor potential of zoledronic acid. Breast 2003;12(suppl 2):S30-36.

7 Zografos GN, Georgiadou D, Thomas D, Kaltsas G, Digalakis M. Drug-induced esophagitis. Dis Esophagus 2009;22:633-37.

8 Wysowski DK. Reports of esophageal cancer with oral bisphosphonate use. N Engl J Med 2009;360:89-90.

9 Abrahamsen B, Eiken P. Eastell R. More on reports of esophageal cancer with oral bisphosphonate use. N Engl J Med 2009;360:1791-92.

10 Green J, Czanner G, Reeves G, Watson J, Wise L, Beral V. Oral bisphosphonates and risk of cancer of oesophagus, stomach, and colorectum: case-control analysis within a UK primary care cohort. BMJ 2010;341:c4444.

11 Cardwell CR, Abnet CC, Cantwell MM, Murray LJ. Exposure to oral bisphosphonates and risk of esophageal cancer. JAMA 2010;304:657-63.

12 Cardwell CR, Abnet CC, Veal P, Hughes CM, Cantwell MM, Murray LJ. Exposure to oral bisphosphonates and risk of cancer. Int J Cancer 2012;131:E717-25.

13 Vestergaard $P$. Occurrence of gastrointestinal cancer in users of bisphosphonates and other antiresorptive drugs against osteoporosis. Calcif Tissue Int 2011;89:434-41.

14 Abrahamsen B, Pazianas M, Eiken P, Russell RGG, Eastell R. Esophageal and gastric cancer incidence and mortality in alendronate users. J Bone Mineral Res 2011:27:679-86.

15 Rennert G, Pinchev M, Rennert HS, Gruber SB. Use of bisphosphonates and reduced risk of colorectal cancer. J Clin Oncol 2011;29:1146-50.

16 Pazianas M, Abrahamsen B, Eiken P, Eastell R, Russell R. Reduced colon cancer incidence and mortality in postmenopausal women treated with an oral bisphosphonate-Danish National Register Based Cohort Study. Osteoporos Int :2012;23:2693-701.

17 Vinogradova Y, Coupland C, Hippisley-Cox J. Exposure to bisphosphonates and risk of cancer: a protocol for nested case-control studies using the QResearch primary care database. BMJ Open 2012;2:e000548.

18 Hippisley-Cox J, Hammersley V, Pringle M, Coupland C, Crown N, Wright L. How useful are general practice databases for research? Analysis of their accuracy and completeness in one research network. Health Inform J 2004:10:91-109.

19 Jick SS, Kaye JA, Vasilakis-Scaramozza C, Rodríguez LAG, Ruigómez A, Meier CR, et al. Validity of the general practice research database. Pharmacotherapy 2003;23:686-9.

20 Hippisley-Cox J, Coupland C. Unintended effects of statins in men and women in England and Wales: population based cohort study using the QResearch database $B M J$ 2010;340:c2197.

21 Parker C, Coupland C, Hippisley-Cox J. Antipsychotic drugs and risk of venous thromboembolism: nested case-control study. BMJ 2010:341:c4245.

22 Walker AJ, Card T, Bates TE, Muir K. Tricyclic antidepressants and the incidence of certain cancers: a study using the GPRD. Br J Cancer 2011;104:193-97.

23 Recker RR, Gallagher R, MacCosbe PE. Effect of dosing frequency on bisphosphonate medication adherence in a large longitudinal cohort of women. Mayo Clin Proc 2005;80:856-61.

24 Henderson KD, Bernstein L. Etiology of cancer: obesity and physical activity. In: DeVita, Hellman, and Rosenberg's Cancer: principles and practice of oncology. Wolters Kluwer/Lippincott Williams and Wilkins, 2008:239-44.

25 Hecht SS. Etiology of cancer: tobacco. In: DeVita, Hellman, and Rosenberg's Cancer: principles and practice of oncology. Wolters Kluwer/Lippincott Williams and Wilkins, 2008:147-55.

26 Schütze M, Boeing H, Pischon T, Rehm J, Kehoe T, Gmel G, et al. Alcohol attributable burden of incidence of cancer in eight European countries based on results from prospective cohort study. BMJ 2011;342:d1584.

27 Ferlay J, Shin H-R, Bray F, Forman D, Mathers C, Parkin DM. Estimates of worldwide burden of cancer in 2008: GLOBOCAN 2008. Int J Cancer 2010;127:2893-917.

28 McGlynn KA, Gridley G, Mellemkjaer L, Brinton LA, Anderson KC, Caporaso NE, et al. Risks of cancer among a cohort of 23,935 men and women with osteoporosis. Int $J$ Cancer 2008;122:1879-84

29 Corley DA, Kubo A, Zhao W, Quesenberry C. Proton pump inhibitors and histamine-2 receptor antagonists are associated with hip fractures among at-risk patients. Gastroenterology 2010;139:93-101.

30 Rodríguez LAG, Lagergren J, Lindblad M. Gastric acid suppression and risk of oesophageal and gastric adenocarcinoma: a nested case control study in the UK. Gut 2006:55:1538-44.

31 Coussens LM, Werb Z. Inflammation and cancer. Nature 2002;420:860-67.

32 Gonzalez-Perez A, Garcia Rodriguez L, Lopez-Ridaura R. Effects of non-steroidal anti-inflammatory drugs on cancer sites other than the colon and rectum: a meta-analysis. BMC Cancer 2003;3:28.

33 Mocellin S. Vitamin D and cancer: deciphering the truth. Biochim Biophys Acta 2011;1816:172-8.

34 Thomas E, Brewster DH, Black RJ, Macfarlane GJ. Risk of malignancy among patients with rheumatic conditions. Int $J$ Cancer 2000;88:497-502.

35 Stattin P, Björ O, Ferrari P, Lukanova A, Lenner P, Lindahl B, et al. Prospective study of hyperglycemia and cancer risk. Diabetes Care 2007;30:561-7.

36 Rustgi AK. Cancers of the gastrointestinal tract. DeVita, Hellman, and Rosenberg's Cancer: principles and practice of oncology Wolters Kluwer/Lippincott Williams and Wilkins, 2008:989-1313.

37 Mai PL, Garceau AO, Graubard BI, Dunn M, McNeel TS, Gonsalves L, et al. Confirmation of family cancer history reported in a population-based survey. J Natl Cancer Inst 2011;103:788-97.

38 Chang ET, Smedby KE, Hjalgrim H, Glimelius B, Adami H-O. Reliability of self-reported family history of cancer in a large case-control study of lymphoma. J Natl Cancer Inst 2006:98:61-8.

39 Royston P. Multiple imputation of missing values. Stata J 2004;4:227-41

40 Royston P. Multiple imputation of missing values: update of ICE. Stata J 2005;5:527-36.

41 Herrett E, Thomas SL, Schoonen WM, Smeeth L, Hall AJ. Validation and validity of diagnoses in the General Practice Research Database: a systematic review. Br J Clin Pharmacol 2010;69:4-14. 


\section{What is already known on this topic}

Bisphosphonates have become a common treatment for osteoporosis

Although preclinical studies have shown bisphosphonates have anti-tumour properties, epidemiological evidence concerning the associations between bisphosphonates and risk of gastrointestinal cancers has not been consistent

\section{What this study adds}

This series of nested case-control studies was conducted with two large general population primary care databases and found no overall association between use of bisphosphonates and risk of oesophageal, gastric, or colorectal cancers

An increased risk of gastric cancer associated with use of alendronate was found in one database, but with no evidence of a duration response

42 Pascoe S, Neal R, Heywood P, Allgar V, Miles J, Stefoski-Mikeljevic J. Identifying patients with a cancer diagnosis using general practice medical records and cancer registry data. Fam Pract 2008;25:215-20.

43 Vestergaard P, Schwartz K, Pinholt E, Rejnmark L, Mosekilde L. Gastric and esophagus events before and during treatment of osteoporosis. Calcif Tissue Int 2010;86:110-5.

44 Mauck KF, Clarke BL. Diagnosis, screening, prevention, and treatment of osteoporosis. Mayo Clin Proc 2006;81:662-72.

45 Hippisley-Cox J, Coupland C. Predicting risk of osteoporotic fracture in men and women in England and Wales: prospective derivation and validation of QFractureScores. BMJ 2009;339:b4229.

46 Wright E, Schofield PT, Seed P, Molokhia M. Bisphosphonates and risk of upper gastrointestinal cancer-a case control study using the General Practice Research Database (GPRD). PLOS ONE 2012;7:e47616.

47 Ho Y-F, Lin J-T, Wu C-Y. Oral Bisphosphonates and risk of esophageal cancer: a dose-intensity analysis in a nationwide population. Cancer Epidemiol Biomarkers Prev 2012;21:993-5.
48 Thomson ABR, Marshall JK, Hunt RH, Provenza JM, Lanza FL, Royer MG, et al. 14 day endoscopy study comparing risedronate and alendronate in postmenopausal women stratified by Helicobacter pylori status. J Rheumatol 2002;29:1965-74.

49 Khalili H, Huang ES, Ogino S, Fuchs CS, AT C. A prospective study of bisphosphonate use and risk of colorectal cancer. J Clin Oncol 2012;30:3229-33.

Accepted: 18 December 2012

\section{Cite this as: BMJ 2013;356:f114}

This is an open-access article distributed under the terms of the Creative Commons Attribution Non-commercial License, which permits use, distribution, and reproduction in any medium, provided the original work is properly cited, the use is non commercial and is otherwise in compliance with the license. See: http://creativecommons.org/licenses/bync/2.0/ and http://creativecommons.org/licenses/by-nc/2.0/legalcode. 


\section{Tables}

Table 1| Baseline demographic characteristics in cases (all gastrointestinal cancers) and all matched controls by database (QResearch or CPRD). Values are percentages and numbers

\begin{tabular}{|c|c|c|c|c|}
\hline & \multicolumn{2}{|c|}{ QResearch } & \multicolumn{2}{|c|}{ CPRD } \\
\hline & Cases ( $n=28$ 625) & Controls $(n=133770)$ & Cases $(n=27324)$ & Controls $(n=27850)$ \\
\hline \multicolumn{5}{|l|}{ Sex: } \\
\hline Male & $59.9(17$ 146) & $59.9(80083)$ & $58.1(15871)$ & 58.1 (74 310) \\
\hline Female & $40.1(11479)$ & $40.1(53687)$ & $41.9(11453)$ & $41.9(53540)$ \\
\hline \multicolumn{5}{|l|}{ Age band (years): } \\
\hline $50-54$ & $4.9(1401)$ & $4.8(6455)$ & $4.9(1338)$ & $4.9(6247)$ \\
\hline $55-64$ & $20.5(5876)$ & $20.5(27424)$ & $20.1(5502)$ & $20.3(25954)$ \\
\hline $65-74$ & 33.6 (9632) & $34.0(45511)$ & $31.7(8668)$ & $32.3(41286)$ \\
\hline $75-84$ & $34.0(9723)$ & $34.2(45688)$ & $32.1(8765)$ & $32.5(41491)$ \\
\hline$\geq 85$ & $7.0(1993)$ & $6.5(8692)$ & $11.2(3051)$ & $10.1(12872)$ \\
\hline \multicolumn{5}{|l|}{ Ethnicity: } \\
\hline White & $23.1(6600)$ & 21.1 (28 228) & $7.7(2107)$ & 7.1 (9069) \\
\hline Not recorded ${ }^{*}$ & $76.0(21754)$ & $77.8(104022)$ & $88.9(24281)$ & 89.6 (114 513) \\
\hline Other & $0.9(271)$ & $1.1(1520)$ & $3.4(936)$ & $3.3(4268)$ \\
\hline Asian & $0.4(111)$ & $0.6(741)$ & $0.2(45)$ & $0.3(414)$ \\
\hline Black & $0.4(103)$ & $0.4(506)$ & $0.1(40)$ & $0.1(169)$ \\
\hline Other & $0.2(57)$ & $0.2(273)$ & $3.1(851)$ & $2.9(3685)$ \\
\hline \multicolumn{5}{|c|}{ Deprivation (5th of Townsend score): } \\
\hline 1 (most affluent) $\dagger$ & $25.4(7059)$ & $26.1(33900)$ & $28.0(2737)$ & $29.6(13542)$ \\
\hline $2^{*}$ & $21.4(5944)$ & $22.5(29$ 169) & $24.2(2358)$ & $24.0(10970)$ \\
\hline $3^{*}$ & $20.7(5768)$ & $20.2(26163)$ & $20.1(1966)$ & $19.8(9029)$ \\
\hline $4^{*}$ & $18.3(5099)$ & $17.8(23131)$ & $16.4(1605)$ & $15.8(7212)$ \\
\hline 5 , most deprived $\dagger$ & $14.2(3966)$ & $13.4(17376)$ & $11.2(1092)$ & $10.8(4922)$ \\
\hline Not recorded & $2.8(789)$ & $3.0(4031)$ & $64.3(17566)$ & $64.3(82$ 175) \\
\hline
\end{tabular}

${ }^{*}$ Assumed white for analyses.

†Proportion only within recorded data. 
Table 2| Baseline characteristics in cases (all gastrointestinal cancers) and all matched controls by database (QResearch or CPRD). Values are percentages and numbers unless stated otherwise

QResearch CPRD

Cases ( $n=28$ 625) Controls $(n=133770)$

Cases $(n=27324)$ Controls $(n=127850)$

Body mass index (BMI):

\begin{tabular}{|c|c|c|c|c|}
\hline $15-24^{*}$ & 35.0 (7729) & 36.2 (35 826) & 36.4 (8242) & 37.7 (39 188) \\
\hline $25-29^{*}$ & $42.0(9290)$ & $42.1(41650)$ & $41.4(9363)$ & $41.6(43319)$ \\
\hline $30-49^{*}$ & $23.0(5088)$ & 21.7 (21 424) & $22.2(5029)$ & 20.7 (21 535) \\
\hline Not recorded & $22.8(6518)$ & 26.1 (34 870) & $17.2(4690)$ & $18.6(23808)$ \\
\hline Years since recorded $†$ & $2.6(1.5-5.6)$ & $2.7(1.5-5.9)$ & $2.6(1.5-5.9)$ & $2.8(1.5-6.2)$ \\
\hline \multicolumn{5}{|l|}{ Smoking status: } \\
\hline Non-smoker* & $43.1(11230)$ & 47.3 (55 708) & $50.1(12904)$ & $54.4(63608)$ \\
\hline Ex-smoker ${ }^{*}$ & 39.4 (10 268) & $37.2(43894)$ & $33.5(8621)$ & 30.8 (35 979) \\
\hline Current light* & $6.1(1591)$ & $5.5(6485)$ & $3.8(985)$ & $3.6(4200)$ \\
\hline Current moderate ${ }^{\star}$ & $7.5(1958)$ & $6.7(7870)$ & $8.7(2233)$ & $7.9(9217)$ \\
\hline Current heavy* & $3.9(1010)$ & $3.3(3919)$ & $3.9(997)$ & $3.4(3927)$ \\
\hline Not recorded & $9.0(2568)$ & $11.9(15894)$ & $5.8(1584)$ & $8.5(10919)$ \\
\hline Years since recorded $†$ & $0.9(0.3-3.0)$ & $1.1(0.4-3.6)$ & $1.0(0.3-3.2)$ & $1.2(0.4-3.8)$ \\
\hline \multicolumn{5}{|l|}{ Use of alcohol: } \\
\hline No use ${ }^{*}$ & 30.5 (6925) & 30.8 (31 788) & $26.4(6114)$ & $27.0(28540)$ \\
\hline Ex-user ${ }^{*}$ & - & - & $2.6(601)$ & $2.4(2489)$ \\
\hline Light $^{\star}$ & $57.8(13140)$ & $59.8(61764)$ & 55.7 (12 924) & $57.3(60633)$ \\
\hline Moderate and more ${ }^{*}$ & $11.7(2653)$ & $9.4(9731)$ & $15.4(3564)$ & $13.4(14192)$ \\
\hline Not recorded & $20.6(5907)$ & $22.8(30487)$ & $15.1(4121)$ & $17.2(21996)$ \\
\hline Years since recorded $\dagger$ & $2.1(0.6-5.5)$ & $2.4(0.7-6.0)$ & $3.0(0.9-7.0)$ & $3.3(1.0-7.4)$ \\
\hline
\end{tabular}

*Proportion only within recorded data.

$\ddagger$ Median (interquartile range) time in years between recorded value and index date. 
Table 3| Medical history at baseline in cases (all gastrointestinal cancers) and all matched controls by database (QResearch or CPRD). Values are percentages and numbers.

QResearch

Cases $(n=28625)$ Controls $(n=133770)$
CPRD

Cases $(n=27324)$ Controls $(n=127850)$

Comorbidities

\begin{tabular}{|c|c|c|c|c|}
\hline Upper gastrointestinal & 22.1 (6339) & 20.1 (26 935) & $29.3(8016)$ & $26.8(34$ 247) \\
\hline Oesophagitis & $7.3(2103)$ & $6.3(8475)$ & $7.4(2032)$ & $6.1(7846)$ \\
\hline Oesophageal ulcer & $0.3(86)$ & $0.1(176)$ & $0.4(109)$ & $0.2(225)$ \\
\hline Barrett's oesophagus & $1.0(299)$ & $0.6(746)$ & $1.1(312)$ & $0.5(691)$ \\
\hline Dysphagia & $1.4(400)$ & $1.1(1440)$ & $2.8(755)$ & $2.3(2954)$ \\
\hline Gastro-oesophageal reflux & $5.6(1593)$ & $5.1(6858)$ & $8.8(2397)$ & $8.0(10223)$ \\
\hline Hiatus hernia & $4.7(1352)$ & $4.2(5560)$ & $6.1(1673)$ & $5.4(6923)$ \\
\hline Gastritis & $2.9(822)$ & $2.7(3630)$ & $3.9(1065)$ & $3.5(4417)$ \\
\hline Peptic ulcer & $6.5(1863)$ & $5.6(7529)$ & $8.0(2179)$ & $6.8(8750)$ \\
\hline Duodenitis & $0.7(199)$ & $0.7(910)$ & $0.9(245)$ & $0.9(1141)$ \\
\hline Dyspepsia & $7.1(2029)$ & $6.6(8839)$ & $12.9(3525)$ & $12.1(15456)$ \\
\hline Diabetes & $11.0(3157)$ & $9.2(12258)$ & $11.3(3093)$ & $9.6(12324)$ \\
\hline Crohn's disease & $0.2(60)$ & $0.2(321)$ & $0.3(70)$ & $0.3(360)$ \\
\hline Ulcerative colitis & $0.9(255)$ & $0.6(836)$ & $0.8(214)$ & $0.7(864)$ \\
\hline Chronic kidney disease & $4.1(1178)$ & $3.9(5277)$ & $4.6(1269)$ & $4.5(5726)$ \\
\hline Rheumatoid arthritis & $1.5(422)$ & $1.6(2081)$ & $1.7(471)$ & $1.7(2233)$ \\
\hline \multicolumn{5}{|l|}{ History of osteoporosis } \\
\hline Osteoporosis/osteopenia & $4.0(1146)$ & $4.1(5501)$ & $4.6(1269)$ & $4.7(5985)$ \\
\hline Osteoporotic fractures & $3.9(1128)$ & $4.0(5326)$ & $3.0(811)$ & 2.9 (3699) \\
\hline \multicolumn{5}{|l|}{ Family history of cancer } \\
\hline Colorectal cancer & $0.3(73)$ & $0.2(238)$ & $0.3(85)$ & $0.3(360)$ \\
\hline Gastrointestinal cancer & $1.1(315)$ & $0.9(1217)$ & $0.3(74)$ & $0.2(220)$ \\
\hline \multicolumn{5}{|c|}{ Drugs used (excluding last 6 months) } \\
\hline Acid lowering drugs & $38.4(10980)$ & 33.7 (45 048) & $40.6(11099)$ & $36.0(45968)$ \\
\hline NSAIDs & $53.8(15394)$ & $54.1(72346)$ & $58.6(16012)$ & $59.3(75769)$ \\
\hline Corticosteroids & $15.1(4330)$ & $13.6(18129)$ & $14.4(3929)$ & $13.1(16696)$ \\
\hline Calcium & $1.1(311)$ & $1.1(1534)$ & $7.5(2057)$ & $7.6(9667)$ \\
\hline Vitamin D & $5.7(1634)$ & $5.6(7490)$ & $6.0(1629)$ & $6.1(7736)$ \\
\hline \multicolumn{5}{|l|}{ Bisphosphonates } \\
\hline Any & $4.6(1322)$ & $4.5(5996)$ & $4.8(1303)$ & $4.6(5868)$ \\
\hline Alendronate & $3.2(906)$ & $3.0(3976)$ & $3.3(894)$ & $3.2(4038)$ \\
\hline Etidronate & $1.6(451)$ & $1.6(2160)$ & $1.4(391)$ & $1.4(1850)$ \\
\hline Risedronate & $1.0(273)$ & $1.0(1301)$ & $1.1(287)$ & $1.0(1236)$ \\
\hline Ibandronate & $0.1(24)$ & $0.1(134)$ & $0.1(24)$ & $0.1(103)$ \\
\hline \multicolumn{5}{|l|}{ Other osteoporosis drugs } \\
\hline Any & $0.3(94)$ & $0.3(451)$ & $0.4(116)$ & $0.4(506)$ \\
\hline Raloxifen & $0.2(59)$ & $0.2(261)$ & $0.2(62)$ & $0.2(289)$ \\
\hline Strontium & $0.1(26)$ & $0.1(137)$ & $0.2(46)$ & $0.1(172)$ \\
\hline Calcitonin & $0.0(14)$ & $0.1(77)$ & $0.0(13)$ & $0.1(71)$ \\
\hline
\end{tabular}

NSAIDs=non-steroidal anti-inflammatory drugs 
Table 4| Bisphosphonate use in oesophageal cancer cases and controls, numbers and odds ratios (95\% confidence intervals) compared with non-use by database

\begin{tabular}{|c|c|c|c|c|c|c|c|c|}
\hline & \multicolumn{3}{|c|}{ QResearch } & \multicolumn{3}{|c|}{ CPRD } & \multicolumn{2}{|c|}{ Combined analysis } \\
\hline & Cases/controls & $\begin{array}{l}\text { Adjusted odds } \\
\text { ratio }(95 \% \mathrm{Cl})\end{array}$ & $P$ value & Cases/controls & $\begin{array}{l}\text { Adjusted* odds } \\
\text { ratio }(95 \% \mathrm{Cl})\end{array}$ & $P$ value & $\begin{array}{c}\text { Pooled } \\
\text { odds ratio }(95 \% \mathrm{Cl})\end{array}$ & $P$ value \\
\hline Total & $5364 / 25101$ & - & - & $5132 / 24053$ & - & - & - & - \\
\hline \multicolumn{9}{|l|}{ Overall use } \\
\hline None & $5112 / 24030$ & - & - & $4870 / 23110$ & - & - & - & - \\
\hline $\begin{array}{l}\text { At least } 1 \\
\text { prescription }\end{array}$ & $252 / 1071$ & 0.97 (0.79 to 1.18$)$ & 0.7 & $262 / 943$ & $1.18(0.97$ to 1.43$)$ & 0.09 & 1.07 (0.93 to 1.23$)$ & 0.3 \\
\hline \multicolumn{9}{|l|}{ Regimen of use } \\
\hline Daily & $103 / 387$ & 1.09 (0.84 to 1.40$)$ & 0.5 & $96 / 337$ & $1.16(0.89$ to 1.51$)$ & 0.3 & $1.12(0.93$ to 1.35$)$ & 0.2 \\
\hline $\begin{array}{l}\text { Weekly or } \\
\text { monthly }\end{array}$ & $149 / 684$ & $0.88(0.70$ to 1.12$)$ & 0.3 & $166 / 606$ & $1.20(0.95$ to 1.50$)$ & 0.1 & 1.03 (0.88 to 1.22$)$ & 0.7 \\
\hline \multicolumn{9}{|l|}{ Duration of use } \\
\hline $\begin{array}{l}\text { Short term }(<1 \\
\text { year) }\end{array}$ & $94 / 367$ & $1.03(0.80$ to 1.34$)$ & 0.8 & $89 / 361$ & 1.05 (0.81 to 1.37$)$ & 0.7 & $1.04(0.87$ to 1.25$)$ & 0.7 \\
\hline $\begin{array}{l}\text { Long term ( } \geq 1 \\
\text { year) }\end{array}$ & $158 / 704$ & $0.92(0.73$ to 1.16$)$ & 0.5 & $173 / 582$ & 1.28 (1.02 to 1.60$)$ & 0.03 & 1.09 (0.93 to 1.28$)$ & 0.3 \\
\hline 1-6 months & $55 / 226$ & $1.00(0.72$ to 1.38$)$ & 1.0 & $58 / 222$ & $1.12(0.82$ to 1.54$)$ & 0.5 & $1.06(0.84$ to 1.33$)$ & 0.6 \\
\hline 7-36 months & $122 / 512$ & $0.97(0.76$ to 1.23$)$ & 0.8 & $112 / 428$ & $1.10(0.86$ to 1.41$)$ & 0.4 & 1.03 (0.87 to 1.22$)$ & 0.7 \\
\hline 37-72 months & $49 / 234$ & $0.90(0.63$ to 1.28$)$ & 0.6 & $63 / 211$ & $1.31(0.94$ to 1.81$)$ & 0.1 & $1.10(0.87$ to 1.40$)$ & 0.4 \\
\hline$>72$ months & $26 / 99$ & $1.02(0.63$ to 1.64$)$ & 0.9 & $29 / 82$ & 1.63 (1.03 to 2.59$)$ & 0.04 & $1.30(0.93$ to 1.81$)$ & 0.1 \\
\hline $\begin{array}{l}\text { Trend for months } \\
\text { of use }\end{array}$ & - & - & 1.0 & - & - & 0.07 & - & 0.2 \\
\hline \multicolumn{9}{|l|}{ Alendronate } \\
\hline Any use & $163 / 721$ & $0.91(0.73$ to 1.14$)$ & 0.4 & $167 / 650$ & $1.03(0.83$ to 1.28$)$ & 0.8 & 0.97 (0.83 to 1.13$)$ & 0.7 \\
\hline$<1$ year & $81 / 309$ & $1.03(0.78$ to 1.37$)$ & 0.8 & $72 / 297$ & 0.97 (0.73 to 1.30$)$ & 0.8 & $1.00(0.82$ to 1.23$)$ & 1.0 \\
\hline$\geq 1$ year & $82 / 412$ & $0.82(0.62$ to 1.08$)$ & 0.2 & $95 / 353$ & $1.10(0.84$ to 1.44$)$ & 0.5 & $0.95(0.78$ to 1.16$)$ & 0.6 \\
\hline $\begin{array}{l}\text { Trend for months } \\
\text { of use }\end{array}$ & - & - & 0.2 & - & - & 0.1 & - & 0.8 \\
\hline \multicolumn{9}{|l|}{ Etidronate } \\
\hline Any use & $99 / 363$ & $1.17(0.91$ to 1.50$)$ & 0.2 & 89/306 & $1.11(0.85$ to 1.45$)$ & 0.4 & 1.14 (0.95 to 1.37$)$ & 0.2 \\
\hline$<1$ year & $35 / 141$ & $1.02(0.69$ to 1.51$)$ & 0.9 & $34 / 126$ & $1.06(0.71$ to 1.58$)$ & 0.8 & $1.04(0.79$ to 1.37$)$ & 0.8 \\
\hline$\geq 1$ year & $64 / 222$ & 1.24 (0.91 to 1.69$)$ & 0.2 & $55 / 180$ & $1.15(0.82$ to 1.60$)$ & 0.4 & 1.20 (0.96 to 1.50$)$ & 0.1 \\
\hline $\begin{array}{l}\text { Trend for months } \\
\text { of use }\end{array}$ & - & - & 0.04 & - & - & 0.6 & - & 0.06 \\
\hline \multicolumn{9}{|l|}{ Risedronate } \\
\hline Any use & $50 / 236$ & $0.82(0.59$ to 1.16$)$ & 0.3 & $60 / 207$ & $1.14(0.83$ to 1.57$)$ & 0.4 & 0.98 (0.78 to 1.24$)$ & 0.9 \\
\hline$<1$ year & $22 / 107$ & 0.79 (0.48 to 1.29$)$ & 0.3 & $24 / 103$ & 0.91 (0.57 to 1.45$)$ & 0.7 & 0.85 (0.60 to 1.19$)$ & 0.3 \\
\hline$\geq 1$ year & $28 / 129$ & $0.81(0.52$ to 1.26$)$ & 0.4 & $36 / 104$ & 1.39 (0.93 to 2.09$)$ & 0.1 & $1.09(0.80$ to 1.46$)$ & 0.6 \\
\hline $\begin{array}{l}\text { Trend for months } \\
\text { of use }\end{array}$ & - & - & 0.1 & - & - & 0.3 & - & 0.9 \\
\hline
\end{tabular}

†Adjusted for BMI, smoking status, alcohol consumption, ethnicity, rheumatoid arthritis, osteoporosis and fractures, use of other osteoporosis drugs, vitamin D, NSAIDs, corticosteroids, acid lowering drugs, years of data, and family history of gastrointestinal cancer. 
Table 5| Bisphosphonate use in gastric cancer cases and controls, numbers and odds ratios ( $95 \%$ confidence intervals) compared to non-use by database

\begin{tabular}{|c|c|c|c|c|c|c|c|c|}
\hline & \multicolumn{3}{|c|}{ QResearch } & \multicolumn{3}{|c|}{ CPRD } & \multicolumn{2}{|c|}{ Combined analysis } \\
\hline & Cases/controls & $\begin{array}{l}\text { Adjusted }^{*} \text { odds } \\
\text { ratio }(95 \% \mathrm{Cl})\end{array}$ & $P$ value & Cases/controls & $\begin{array}{l}\text { Adjusted* odds } \\
\text { ratio }(95 \% \mathrm{Cl})\end{array}$ & $P$ value & $\begin{array}{l}\text { Pooled odds ratio } \\
\qquad(95 \% \mathrm{Cl})\end{array}$ & $P$ value \\
\hline Total & $3155 / 14715$ & - & - & $3157 / 14686$ & - & - & - & - \\
\hline \multicolumn{9}{|l|}{ Overall use } \\
\hline None & $3014 / 14135$ & - & - & 3018/13992 & - & - & - & - \\
\hline $\begin{array}{l}\text { At least } 1 \\
\text { prescription }\end{array}$ & $141 / 580$ & 1.12 (0.87 to 1.44$)$ & 0.4 & $139 / 694$ & 0.79 (0.62 to 1.01$)$ & 0.06 & 0.93 (0.78 to 1.11$)$ & 0.4 \\
\hline \multicolumn{9}{|l|}{ Regimen of use } \\
\hline Daily & $56 / 226$ & $1.18(0.84$ to 1.67$)$ & 0.3 & $38 / 247$ & 0.60 (0.41 to 0.87$)$ & 0.008 & 0.87 (0.67 to 1.12 ) & 0.3 \\
\hline $\begin{array}{l}\text { Weekly or } \\
\text { monthly }\end{array}$ & $85 / 354$ & $1.07(0.79$ to 1.45$)$ & 0.6 & $101 / 447$ & 0.91 (0.69 to 1.19$)$ & 0.5 & $0.98(0.80$ to 1.20$)$ & 0.8 \\
\hline \multicolumn{9}{|l|}{ Duration of use } \\
\hline $\begin{array}{l}\text { Short term }(<1 \\
\text { year) }\end{array}$ & $62 / 195$ & $1.37(0.98$ to 1.90$)$ & 0.07 & $60 / 279$ & 0.84 (0.61 to 1.15$)$ & 0.3 & $1.06(0.84$ to 1.33$)$ & 0.6 \\
\hline $\begin{array}{l}\text { Long term }(\geq 1 \\
\text { year) }\end{array}$ & $79 / 385$ & 0.96 (0.71 to 1.31$)$ & 0.8 & $79 / 415$ & 0.75 (0.56 to 1.01$)$ & 0.06 & 0.85 (0.68 to 1.05$)$ & 0.1 \\
\hline 1-6 months & $33 / 109$ & 1.32 (0.86 to 2.02 ) & 0.2 & $37 / 170$ & 0.85 (0.58 to 1.26$)$ & 0.4 & 1.04 (0.78 to 1.38$)$ & 0.8 \\
\hline 7-36 months & $73 / 285$ & $1.13(0.83$ to 1.53$)$ & 0.4 & $76 / 332$ & $0.90(0.67$ to 1.20$)$ & 0.5 & $1.00(0.81$ to 1.24$)$ & 1.0 \\
\hline 37-72 months & $23 / 131$ & 0.83 (0.50 to 1.36$)$ & 0.5 & $20 / 138$ & 0.53 (0.32 to 0.89$)$ & 0.02 & $0.67(0.47$ to 0.95$)$ & 0.03 \\
\hline$>72$ months & $12 / 55$ & $1.23(0.62$ to 2.41$)$ & 0.6 & $6 / 54$ & 0.43 (0.18 to 1.03$)$ & 0.06 & 0.83 (0.49 to 1.41$)$ & 0.5 \\
\hline $\begin{array}{l}\text { Trend for months } \\
\text { of use }\end{array}$ & - & - & 0.8 & - & - & 0.02 & - & 0.08 \\
\hline \multicolumn{9}{|l|}{ Alendronate } \\
\hline Any use & $102 / 361$ & $1.47(1.11$ to 1.95$)$ & 0.008 & $100 / 457$ & 0.93 (0.71 to 1.22 ) & 0.6 & $1.16(0.95$ to 1.41$)$ & 0.1 \\
\hline$<1$ year & $59 / 153$ & 1.91 (1.34 to 2.72 ) & $<0.001$ & $47 / 212$ & 0.94 (0.66 to 1.34$)$ & 0.7 & 1.34 (1.05 to 1.73$)$ & 0.02 \\
\hline$\geq 1$ year & $43 / 208$ & $1.08(0.74$ to 1.59$)$ & 0.7 & $53 / 245$ & 0.93 (0.66 to 1.31$)$ & 0.7 & 0.99 (0.77 to 1.28$)$ & 1.0 \\
\hline $\begin{array}{l}\text { Trend for months } \\
\text { of use }\end{array}$ & - & - & 0.6 & - & - & 0.1 & - & 0.5 \\
\hline \multicolumn{9}{|l|}{ Etidronate } \\
\hline Any use & $49 / 222$ & 0.93 (0.65 to 1.32 ) & 0.7 & $31 / 212$ & 0.59 (0.39 to 0.88$)$ & 0.01 & 0.76 (0.58 to 0.99$)$ & 0.05 \\
\hline$<1$ year & $26 / 87$ & $1.20(0.75$ to 1.94$)$ & 0.4 & $15 / 97$ & 0.62 (0.35 to 1.08$)$ & 0.09 & 0.91 (0.63 to 1.31$)$ & 0.6 \\
\hline$\geq 1$ year & $23 / 135$ & 0.76 (0.47 to 1.22$)$ & 0.3 & $16 / 115$ & 0.56 (0.33 to 0.98$)$ & 0.04 & 0.67 (0.47 to 0.96$)$ & 0.03 \\
\hline $\begin{array}{l}\text { Trend for months } \\
\text { of use }\end{array}$ & - & - & 0.6 & - & - & 0.04 & - & 0.1 \\
\hline \multicolumn{9}{|l|}{ Risedronate } \\
\hline Any use & $29 / 137$ & 0.84 (0.54 to 1.30$)$ & 0.4 & $29 / 149$ & $0.83(0.54$ to 1.27$)$ & 0.4 & 0.83 (0.61 to 1.13$)$ & 0.2 \\
\hline$<1$ year & $16 / 67$ & $0.89(0.50$ to 1.60$)$ & 0.7 & $13 / 74$ & 0.75 (0.41 to 1.38$)$ & 0.4 & $0.82(0.54$ to 1.25$)$ & 0.4 \\
\hline$\geq 1$ year & $13 / 70$ & 0.72 (0.39 to 1.35$)$ & 0.3 & $16 / 75$ & 0.91 (0.51 to 1.61 ) & 0.7 & $0.82(0.54$ to 1.25$)$ & 0.3 \\
\hline $\begin{array}{l}\text { Trend for months } \\
\text { of use }\end{array}$ & - & - & 0.5 & - & - & 0.7 & - & 0.5 \\
\hline
\end{tabular}

*Adjusted for body mass index, smoking status, alcohol consumption, ethnicity, rheumatoid arthritis, osteoporosis and fractures, use of other osteoporosis drugs, vitamin D, NSAIDs, corticosteroids, acid lowering drugs, years of data, for family history of gastrointestinal cancer. 
Table $6 \mid$ Bisphosphonate use in cases of colorectal cancer and controls, numbers and odds ratios (95\% confidence intervals) compared with non-use by database

\begin{tabular}{|c|c|c|c|c|c|c|c|c|c|}
\hline & \multicolumn{3}{|c|}{ QResearch } & \multicolumn{3}{|c|}{ CPRD } & \multicolumn{3}{|c|}{ Combined analysis } \\
\hline & Cases/controls & $\begin{array}{l}\text { Adjusted* odds } \\
\text { ratio }(95 \% \mathrm{Cl})\end{array}$ & $P$ value & Cases/controls & $\begin{array}{l}\text { Adjusted* odds } \\
\text { ratio }(95 \% \mathrm{Cl})\end{array}$ & $P$ value & Pooled odds ratio $(95 \% \mathrm{Cl}$ & & $P$ value \\
\hline Total & 20 106/93954 & - & - & 19 035/89 111 & - & - & - & & - \\
\hline \multicolumn{10}{|l|}{ Overall use } \\
\hline None & $19177 / 89609$ & - & - & $18133 / 84880$ & - & - & - & & - \\
\hline $\begin{array}{l}\text { At least } 1 \\
\text { prescription }\end{array}$ & $929 / 4345$ & $1.03(0.94$ to 1.14$)$ & 0.5 & $902 / 4231$ & 1.10 (1.00 to 1.22$)$ & 0.05 & $1.07(1.00$ to 1.14$)$ & & 0.07 \\
\hline \multicolumn{10}{|c|}{ Regimen of use } \\
\hline Daily & $337 / 1607$ & 1.01 (0.88 to 1.15$)$ & 0.9 & $294 / 1430$ & $1.05(0.91$ to 1.21$)$ & 0.5 & 1.03 (0.93 to 1.13$)$ & & 0.6 \\
\hline $\begin{array}{l}\text { Weekly or } \\
\text { monthly }\end{array}$ & $592 / 2738$ & 1.05 (0.93 to 1.18$)$ & 0.4 & $608 / 2801$ & $1.13(1.01$ to 1.27$)$ & 0.03 & 1.09 (1.01 to 1.19$)$ & & 0.03 \\
\hline \multicolumn{10}{|l|}{ Duration of use } \\
\hline $\begin{array}{l}\text { Short term }(<1 \\
\text { year) }\end{array}$ & $345 / 1599$ & 1.02 (0.90 to 1.17$)$ & 0.7 & $358 / 1558$ & $1.17(1.03$ to 1.33$)$ & 0.02 & $1.10(1.00$ to 1.20$)$ & & 0.06 \\
\hline $\begin{array}{l}\text { Long term ( } \geq 1 \\
\text { year) }\end{array}$ & $584 / 2746$ & 1.04 (0.92 to 1.17$)$ & 0.5 & $544 / 2673$ & $1.06(0.94$ to 1.19$)$ & 0.4 & $1.05(0.97$ to 1.14$)$ & & 0.3 \\
\hline $1-6$ months & $212 / 993$ & $1.02(0.87$ to 1.20$)$ & 0.8 & $252 / 1010$ & 1.27 (1.09 to 1.48$)$ & 0.002 & $1.15(1.03$ to 1.28$)$ & & 0.02 \\
\hline 7-36 months & $426 / 1982$ & 1.03 (0.91 to 1.17$)$ & 0.6 & $394 / 1957$ & 1.03 (0.91 to 1.17$)$ & 0.6 & 1.03 (0.95 to 1.13$)$ & & 0.5 \\
\hline 37-72 months & $193 / 957$ & 0.99 (0.83 to 1.18$)$ & 0.9 & $176 / 891$ & $1.03(0.86$ to 1.23$)$ & 0.8 & $1.01(0.89$ to 1.14$)$ & & 0.8 \\
\hline$>72$ months & $98 / 413$ & $1.19(0.94$ to 1.52$)$ & 0.1 & $80 / 373$ & $1.13(0.87$ to 1.46$)$ & 0.3 & $1.16(0.98$ to 1.39$)$ & & 0.09 \\
\hline $\begin{array}{l}\text { Trend for } \\
\text { months of use }\end{array}$ & - & - & 0.3 & - & - & 0.5 & - & & 0.2 \\
\hline \multicolumn{10}{|l|}{ Alendronate } \\
\hline Any use & $641 / 2894$ & 1.10 (0.98 to 1.22$)$ & 0.1 & $627 / 2931$ & 1.10 (0.98 to 1.22$)$ & 0.1 & $\begin{array}{c}1.10(1.01 \text { to } \\
1.19)\end{array}$ & 0.02 & \\
\hline$<1$ year & $305 / 1331$ & 1.13 (0.98 to 1.30$)$ & 0.1 & $283 / 1264$ & 1.12 (0.97 to 1.30$)$ & 0.1 & $\begin{array}{c}1.13(1.02 \text { to } \\
1.25)\end{array}$ & .02 & \\
\hline$\geq 1$ year & $336 / 1563$ & 1.07 (0.93 to 1.23$)$ & 0.3 & $344 / 1667$ & 1.07 (0.93 to 1.23$)$ & 0.3 & $\begin{array}{c}1.07(0.97 \text { to } \\
1.18)\end{array}$ & 0.2 & \\
\hline $\begin{array}{l}\text { Trend for } \\
\text { months of use }\end{array}$ & - & - & 0.2 & - & - & 0.5 & - & 0.2 & \\
\hline \multicolumn{10}{|l|}{ Etidronate } \\
\hline Any use & $303 / 1575$ & 0.90 (0.78 to 1.03$)$ & 0.1 & $271 / 1332$ & 1.00 (0.86 to 1.15$)$ & 1.0 & $\begin{array}{c}0.94(0.86 \text { to } \\
1.04)\end{array}$ & 0.3 & \\
\hline$<1$ year & $114 / 617$ & 0.85 (0.69 to 1.05$)$ & 0.1 & $119 / 569$ & 1.02 (0.83 to 1.26$)$ & 0.8 & $\begin{array}{c}0.93(0.81 \text { to } \\
1.08)\end{array}$ & 0.4 & \\
\hline$\geq 1$ year & $189 / 958$ & 0.93 (0.79 to 1.10$)$ & 0.4 & $152 / 763$ & 0.98 (0.82 to 1.18$)$ & 0.8 & $\begin{array}{c}0.95(0.84 \text { to } \\
1.08)\end{array}$ & 0.5 & \\
\hline $\begin{array}{l}\text { Trend for } \\
\text { months of use }\end{array}$ & - & - & 0.9 & - & - & 0.6 & - & 0.7 & \\
\hline \multicolumn{10}{|l|}{ Risedronate } \\
\hline Any use & $194 / 928$ & 1.00 (0.85 to 1.18$)$ & 1.0 & $198 / 880$ & 1.13 (0.96 to 1.34$)$ & 0.2 & $\begin{array}{c}1.06(0.95 \text { to } \\
1.20)\end{array}$ & 0.3 & \\
\hline$<1$ year & $80 / 442$ & 0.87 (0.68 to 1.12$)$ & 0.3 & $104 / 412$ & 1.27 (1.02 to 1.59$)$ & 0.04 & $\begin{array}{c}1.07(0.91 \text { to } \\
1.27)\end{array}$ & 0.4 & \\
\hline$\geq 1$ year & $114 / 486$ & 1.11 (0.90 to 1.38$)$ & 0.3 & $94 / 468$ & 1.00 (0.79 to 1.26$)$ & 1.0 & $\begin{array}{c}1.06(0.90 \text { to } \\
1.24)\end{array}$ & 0.5 & \\
\hline $\begin{array}{l}\text { Trend for } \\
\text { months of use }\end{array}$ & - & - & 0.7 & - & - & 0.8 & - & 0.9 & \\
\hline
\end{tabular}

*Adjusted for, BMI, smoking status, alcohol consumption, ethnicity, rheumatoid arthritis, osteoporosis and fractures, use of other osteoporosis drugs, vitamin D, NSAIDs, corticosteroids, acid lowering drugs, years of data, and for family history of colorectal cancer, diabetes, colitis, and Crohn's disease. 
Table $7 \mid$ Sensitivity analyses by definition of length of use of bisphosphonates (short term ( $\leq 1$ year) and long term ( $>1$ year)) and varying definitions of use

\begin{tabular}{|c|c|c|c|c|c|c|}
\hline \multirow[b]{2}{*}{ Term of use } & \multicolumn{3}{|c|}{ QResearch } & \multicolumn{3}{|c|}{ CPRD } \\
\hline & $\begin{array}{l}\text { Exposed } \\
\text { cases }\end{array}$ & $\begin{array}{l}\text { Adjusted }{ }^{*} \text { odds ratio } \\
(95 \% \mathrm{Cl})\end{array}$ & $P$ value & $\begin{array}{l}\text { Exposed } \\
\text { cases }\end{array}$ & $\begin{array}{l}\text { Adjusted* odds } \\
\text { ratio }(95 \% \mathrm{Cl})\end{array}$ & $P$ value \\
\hline \multicolumn{7}{|c|}{ Oesophageal cancer } \\
\hline \multicolumn{7}{|c|}{ Use defined as at least 2 prescriptions in observation period } \\
\hline$\leq 1$ year & 74 & $1.03(0.77$ to 1.36$)$ & 0.9 & 65 & $0.88(0.65$ to 1.18$)$ & 0.4 \\
\hline$>1$ year & 158 & $0.92(0.73$ to 1.16$)$ & 0.5 & 173 & $1.23(0.98$ to 1.54$)$ & 0.07 \\
\hline \multicolumn{7}{|c|}{ Use defined as at least 1 prescription before index date } \\
\hline$\leq 1$ year & 111 & 1.23 (0.96 to 1.56$)$ & 0.1 & 103 & $1.17(0.91$ to 1.50$)$ & 0.2 \\
\hline$>1$ year & 171 & $0.94(0.75$ to 1.18$)$ & 0.6 & 182 & 1.23 (0.99 to 1.53$)$ & 0.06 \\
\hline
\end{tabular}

Use defined as at least 1 prescription between 72 and 6 months before index date in patients with at least 6 years of records

\begin{tabular}{lcccccc}
\hline$\leq 1$ year & 75 & $0.99(0.74$ to 1.32$)$ & 0.9 & 78 & $1.09(0.81$ to 1.45$)$ & 0.6 \\
\hline$>1$ year & 142 & $0.93(0.73$ to 1.18$)$ & 0.5 & 145 & $1.26(0.98$ to 1.60$)$ & 0.07
\end{tabular}

\section{Gastric cancer}

Use defined as at least 2 prescriptions in observation period

\begin{tabular}{llllll}
\hline$\leq 1$ year & 53 & $1.49(1.04$ to 2.13$)$ & 0.03 & 50 & $0.75(0.53$ to 1.06$)$ \\
\hline$>1$ year & 79 & $0.97(0.71$ to 1.31$)$ & 0.8 & 79 & $0.73(0.55$ to 0.99$)$ \\
\hline \begin{tabular}{l} 
Use defined as at least 1 prescription before the index date \\
\hline l year
\end{tabular}$\quad 61$ & $1.17(0.84$ to 1.62$)$ & 0.3 & & 0.1 \\
\hline 1 year & 88 & $0.93(0.69$ to 1.25$)$ & 0.6 & 90 & $1.02(0.76$ to 1.38$)$ \\
\hline
\end{tabular}

Use defined as at least 1 prescription between 72 and 6 months before index date in patients with at least 6 years of records

\begin{tabular}{lllllll}
\hline$\leq 1$ year & 54 & $1.21(0.84$ to 1.75$)$ & 0.3 & 52 & $0.85(0.60$ to 1.21$)$ \\
\hline$>1$ year & 66 & $0.90(0.64$ to 1.26$)$ & 0.5 & 65 & $0.72(0.52$ to 0.99$)$ & 0.04 \\
\hline
\end{tabular}

\section{Colorectal cancer}

Use defined as at least 2 prescriptions in observation period

\begin{tabular}{|c|c|c|c|c|c|c|}
\hline$\leq 1$ year & 273 & $1.02(0.88$ to 1.18$)$ & 0.8 & 291 & $1.09(0.94$ to 1.25$)$ & 0.3 \\
\hline$>1$ year & 584 & $1.04(0.92$ to 1.16$)$ & 0.5 & 544 & $1.04(0.92$ to 1.16$)$ & 0.6 \\
\hline \multicolumn{7}{|c|}{ Use defined as at least 1 prescription before index date } \\
\hline$\leq 1$ year & 384 & $1.04(0.92$ to 1.18$)$ & 0.5 & 386 & $1.12(0.99$ to 1.27$)$ & 0.07 \\
\hline$>1$ year & 633 & $1.02(0.91$ to 1.14$)$ & 0.7 & 589 & $1.06(0.94$ to 1.18$)$ & 0.4 \\
\hline
\end{tabular}

Use defined as at least 1 prescription between 72 and 6 months before index date in patients with at least 6 years of records

\begin{tabular}{lllllll}
\hline$\leq 1$ year & 298 & $1.02(0.88$ to 1.18$)$ & 0.8 & 285 & $1.13(0.97$ to 1.30$)$ \\
\hline$>1$ year & 492 & $1.00(0.88$ to 1.13$)$ & 1.0 & 476 & $1.08(0.96$ to 1.23$)$ \\
\hline
\end{tabular}

*Adjusted for BMI, smoking status, alcohol consumption, ethnicity, rheumatoid arthritis, osteoporosis and fractures, use of other osteoporosis drugs, vitamin D, NSAIDs, corticosteroids, acid lowering drugs, and years of data and for family history of colorectal cancer, diabetes, colitis, and Crohn's disease. 